From Daniel M. Green, Cheryl L. Cox, Liang Zhu, Kevin R. Krull, Deo Kumar Srivastava, Gregory T. Armstrong, and Leslie L. Robison, St Jude Children's Research Hospital, Memphis, TN; Marilyn Stovall, The University of Texas MD Anderson Cancer Center, Houston, TX; Sarah S. Donaldson, Stanford University Medical Center, Stanford, CA; Kevin C. Oeffinger and Charles A. Sklar, Memorial Sloan-Kettering Cancer Center, New York, NY; and Lillian R. Meacham, Emory University, Atlanta, GA.

Submitted January 11, 2011; accepted September 16, 2011; published online ahead of print at www.jco.org on December 19, 2011.

Supported by the National Cancer Institute (Grants No. CA-55727, L.L. Robison, principal investigator, and CA-21765, M.B. Kastan, principal investigator) of the National Institutes of Health. Support provided to the University of Minnesota Cancer Center from the Children's Cancer Research Fund and to St Jude Children's Research Hospital by the American Lebanese Syrian Associated Charities.

Authors' disclosures of potential conflicts of interest and author contributions are found at the end of this article.

Corresponding author: Daniel M. Green MD, Department of Epidemiology and Cancer Control, St Jude Children's Research Hospital, 262 Danny Thomas Place, Mail Stop 735, Memphis, TN 38105-2794; e-mail: daniel.green @stjude.org

(C) 2011 by American Society of Clinical Oncology

0732-183X/12/3003-246/\$20.00

DOI: $10.1200 / J C O .2010 .34 .4267$

\title{
Risk Factors for Obesity in Adult Survivors of Childhood Cancer: A Report From the Childhood Cancer Survivor Study
}

Daniel M. Green, Cheryl L. Cox, Liang Zhu, Kevin R. Krull, Deo Kumar Srivastava, Marilyn Stovall, Vikki G. Nolan, Kirsten K. Ness, Sarah S. Donaldson, Kevin C. Oeffinger, Lillian R. Meacham, Charles A. Sklar, Gregory T. Armstrong, and Leslie L. Robison

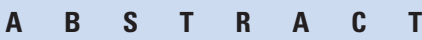

\section{Purpose}

Many Childhood Cancer Survivor Study (CCSS) participants are at increased risk for obesity. The etiology of their obesity is likely multifactorial but not well understood.

\section{Patients and Methods}

We evaluated the potential contribution of demographic, lifestyle, treatment, and intrapersonal factors and self-reported pharmaceutical use to obesity (body mass index $\geq 30 \mathrm{~kg} / \mathrm{m}^{2}$ ) among 9,284 adult ( $>18$ years of age) CCSS participants. Independent predictors were identified using multivariable regression models. Interrelationships were determined using structural equation modeling (SEM)

\section{Results}

Independent risk factors for obesity included cancer diagnosed at 5 to 9 years of age (relative risk [RR], 1.12; 95\% Cl, 1.01 to 1.24; $P=.03$ ), abnormal Short Form-36 physical function (RR, 1.19; $95 \% \mathrm{Cl}, 1.06$ to $1.33 ; P<.001)$, hypothalamic/pituitary radiation doses of 20 to $30 \mathrm{~Gy}(\mathrm{RR}, 1.17$; $95 \% \mathrm{Cl}, 1.05$ to $1.30 ; P=.01)$, and paroxetine use (RR, $1.29 ; 95 \% \mathrm{Cl}, 1.08$ to $1.54 ; P=.01)$. Meeting US Centers for Disease Control and Prevention guidelines for vigorous physical activity (RR, 0.90; 95\% Cl, 0.82 to $0.97 ; P=.01)$ and a medium amount of anxiety (RR, 0.86; $95 \% \mathrm{Cl}, 0.75$ to $0.99 ; P=.04)$ reduced the risk of obesity. Results of SEM ( $N=8,244$; comparative fit index = 0.999; Tucker Lewis index $=0.999$; root mean square error of approximation $=0.014$; weighted root mean square residual $=0.749$ ) described the hierarchical impact of the direct predictors, moderators, and mediators of obesity.

\section{Conclusion}

Treatment, lifestyle, and intrapersonal factors, as well as the use of specific antidepressants, may contribute to obesity among survivors. A multifaceted intervention, including alternative drug and other therapies for depression and anxiety, may be required to reduce risk.

\section{J Clin Oncol 30:246-255. (C) 2011 by American Society of Clinical Oncology}

\section{INTRODUCTION}

Survivors of childhood cancer are at risk for treatment-related sequelae that place them at an increased risk for being obese. Compared with US normative data from the 1995 National Health Interview Survey, risk of obesity (body mass index $[\mathrm{BMI}] \geq 30 \mathrm{~kg} / \mathrm{m}^{2}$ ) was increased $50 \%$ among adult female and 20\% among adult male leukemia survivors in the Childhood Cancer Survivor Study (CCSS). ${ }^{1}$ Among CCSS male survivors, Hispanic race/ethnicity and brain radiation were associated with an increased risk of obesity, whereas age at diagnosis of 5 to 9 years, black, non-Hispanic race/ ethnicity, brain radiation, and treatment with an anthracycline and an alkylating agent increased the risk of obesity among CCSS female survivors. ${ }^{2}$

Survivors treated for acute lymphoblastic leukemia (ALL), Hodgkin's lymphoma (HL), and nonHodgkin's lymphoma (NHL) were more likely to report symptomatic levels on the Brief Symptom Inventory-18 (BSI) depression subscale (ALL, 5.4\%; HL, 5.5\%; and NHL, 4.4\%) than were siblings (3.4\%). Female ALL and HL survivors were approximately twice as likely to report symptomatic levels for depression as compared with male survivors. ${ }^{3}$ CCSS participants with solid tumors had significantly higher scores on the BSI depression, somatic distress, and anxiety subscales than did CCSS sibling participants. ${ }^{4}$ 


\begin{tabular}{|c|c|c|}
\hline \multirow[b]{2}{*}{ Variable } & \multicolumn{2}{|c|}{$\begin{array}{l}\text { Adult Survivors } \\
\qquad(\mathrm{N}=9,284)\end{array}$} \\
\hline & No. & $\%$ \\
\hline \multicolumn{3}{|l|}{ Sex } \\
\hline Male & 4,707 & 50.70 \\
\hline Female & 4,577 & 49.30 \\
\hline \multicolumn{3}{|l|}{ Race/ethnicity } \\
\hline Non-Hispanic white & 8,262 & 89.33 \\
\hline Hispanic & 332 & 3.59 \\
\hline Non-Hispanic black & 394 & 4.26 \\
\hline Other & 261 & 2.82 \\
\hline Missing & 35 & \\
\hline \multicolumn{3}{|l|}{ Education level } \\
\hline No high school or GED & 430 & 4.68 \\
\hline High school or GED & 2,111 & 22.98 \\
\hline Some college; no bachelor's degree & 2,773 & 30.18 \\
\hline Bachelor's degree or higher & 3,873 & 42.16 \\
\hline Missing & 97 & \\
\hline \multicolumn{3}{|l|}{ Age at diagnosis, years } \\
\hline $0-4$ & 3,769 & 41.38 \\
\hline $5-9$ & 2,071 & 22.74 \\
\hline $10-14$ & 1,866 & 20.49 \\
\hline $15-20$ & 1,403 & 15.40 \\
\hline Missing & 175 & \\
\hline \multicolumn{3}{|l|}{ Age at questionnaire, years } \\
\hline $18-25$ & 2,479 & 26.70 \\
\hline $26-35$ & 4,070 & 43.84 \\
\hline $36-45$ & 2,404 & 25.89 \\
\hline $46-55$ & 331 & 3.57 \\
\hline \multicolumn{3}{|l|}{$>55$} \\
\hline \multicolumn{3}{|l|}{ Family income } \\
\hline$<\$ 20,000 /$ year & 1,056 & 13.30 \\
\hline$\geq \$ 20,000$ and $<\$ 40,000 /$ year & 1,870 & 23.55 \\
\hline$\geq \$ 40,000 /$ year & 5,015 & 63.15 \\
\hline Missing & 1,343 & \\
\hline \multicolumn{3}{|l|}{ Health insurance } \\
\hline Yes or Canadian & 8,090 & 87.88 \\
\hline No & 1,116 & 12.12 \\
\hline Missing & 78 & \\
\hline \multicolumn{3}{|c|}{ Baseline frequency of aerobic exercise, days/wk } \\
\hline 0 & 2,786 & 31.13 \\
\hline 1 & 1045 & 11.67 \\
\hline 2 & 1,273 & 14.22 \\
\hline 3 & 1,326 & 14.81 \\
\hline 4 & 807 & 9.02 \\
\hline 5 & 854 & 9.54 \\
\hline 6 & 295 & 3.30 \\
\hline 7 & 565 & 6.31 \\
\hline Missing & 333 & \\
\hline \multicolumn{3}{|l|}{ Physical activity } \\
\hline No & 6,572 & 72.01 \\
\hline Yes & 2,555 & 27.99 \\
\hline Missing & 157 & \\
\hline \multicolumn{3}{|l|}{ Inactive lifestyle } \\
\hline No & 7,140 & 77.21 \\
\hline Yes & 2,107 & 22.79 \\
\hline Missing & 37 & \\
\hline \multicolumn{3}{|c|}{ (continued in next column) } \\
\hline
\end{tabular}

\begin{tabular}{|c|c|c|}
\hline \multirow[b]{2}{*}{ Variable } & \multicolumn{2}{|c|}{$\begin{array}{l}\text { Adult Survivors } \\
(N=9,284)\end{array}$} \\
\hline & No. & $\%$ \\
\hline \multicolumn{3}{|l|}{ Hypothalamic/pituitary radiation dose } \\
\hline None & 2,916 & 35.00 \\
\hline$<20 \mathrm{~Gy}$ & 3,547 & 42.58 \\
\hline$\geq 20$ to $\leq 30 \mathrm{~Gy}$ & 1,111 & 13.34 \\
\hline$>30 \mathrm{~Gy}$ & 757 & 9.09 \\
\hline Missing & 953 & \\
\hline \multicolumn{3}{|l|}{ BSI-18 Depression Score* } \\
\hline$<63$ & 6,805 & 88.11 \\
\hline$\geq 63$ & 918 & 11.89 \\
\hline Missing & 1,561 & \\
\hline \multicolumn{3}{|l|}{ BSI-18 Somatic Distress Score* } \\
\hline$<63$ & 6,644 & 86.06 \\
\hline$\geq 63$ & 1,076 & 13.94 \\
\hline Missing & 1,564 & \\
\hline \multicolumn{3}{|l|}{ BSI-18 Anxiety Score* } \\
\hline$<63$ & 7,120 & 92.20 \\
\hline$\geq 63$ & 602 & 7.80 \\
\hline Missing & 1,562 & \\
\hline \multicolumn{3}{|l|}{ Cancer-related anxiety } \\
\hline No anxiety/fears & 4,751 & 61.60 \\
\hline Small amount of anxiety/fears & 2,089 & 27.08 \\
\hline Medium amount of anxiety/fears & 607 & 7.87 \\
\hline A lot of anxiety/fears & 199 & 2.58 \\
\hline Very many, extreme anxiety/fears & 67 & 0.87 \\
\hline Missing & 1,571 & \\
\hline \multicolumn{3}{|l|}{ Cancer-related pain } \\
\hline No pain & 5,928 & 77.06 \\
\hline Small amount of pain & 962 & 12.50 \\
\hline Medium amount of pain & 526 & 6.84 \\
\hline A lot of pain & 204 & 2.65 \\
\hline Very bad, excruciating pain & 73 & 0.95 \\
\hline Missing & 1,591 & \\
\hline \multicolumn{3}{|l|}{ SF-36 Physical Function } \\
\hline$>40$ & 8,210 & 88.88 \\
\hline$\leq 40$ & 1,027 & 11.12 \\
\hline Missing & 47 & \\
\hline \multicolumn{3}{|l|}{ Fluoxetine } \\
\hline No & 8,939 & 97.63 \\
\hline Yes & 217 & 2.37 \\
\hline Missing & 128 & \\
\hline \multicolumn{3}{|l|}{ Sertraline } \\
\hline No & 8,840 & 96.55 \\
\hline Yes & 316 & 3.45 \\
\hline Missing & 128 & \\
\hline \multicolumn{3}{|l|}{ Paroxetine } \\
\hline No & 8,899 & 97.19 \\
\hline Yes & 257 & 2.81 \\
\hline Missing & 128 & \\
\hline \multicolumn{3}{|l|}{ Citalopram } \\
\hline No & 8,975 & 98.02 \\
\hline Yes & 181 & 1.98 \\
\hline Missing & 128 & \\
\hline \multicolumn{3}{|l|}{ Escitalopram } \\
\hline No & 9,065 & 99.01 \\
\hline Yes & 91 & 0.99 \\
\hline Missing & 128 & \\
\hline (continued ir & & \\
\hline
\end{tabular}




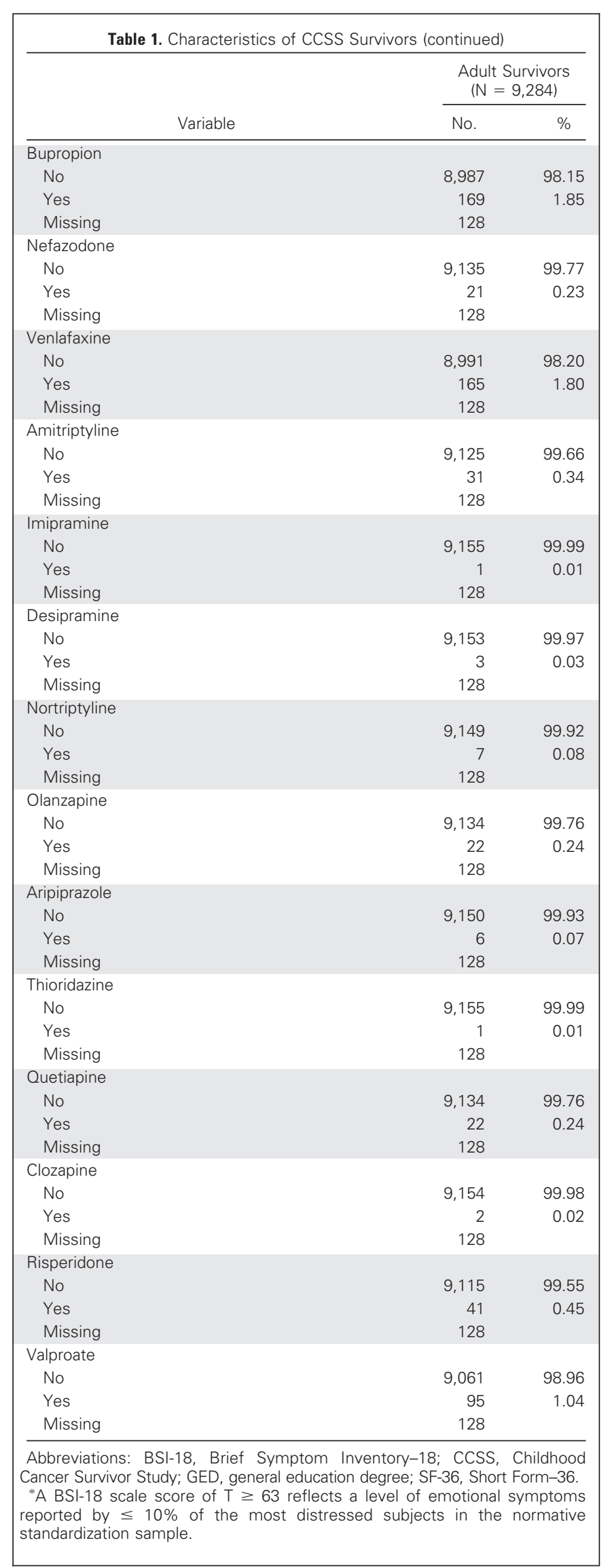

Weight gain is a frequent adverse effect of the use of some antidepressants, including paroxetine (Paxil; GlaxoSmithKline, Research Triangle Park, NC) 5,6 $^{5}$ and, in one study, sertraline (Zoloft; Pfizer Inc, New York, NY), ${ }^{6}$ as well as antipsychotic drugs such as clozapine (Clozaril; Novartis Pharmaceuticals, East Hanover, NJ), olanzapine (Zyprexa; Eli Lilly, Indianapolis, IN), and risperidone (Risperdal; Janssen, Division of Ortho-Mcneil-Janssen Pharmaceuticals Inc, Titusville, $\mathrm{NJ})^{7-18}$ and some drugs used for seizure control and/or mood stabilization, such as sodium valproate (Depakote; Abbott Laboratories, Abbott Park, IL). ${ }^{19-21}$

In addition to treatment, lifestyle, and intrapersonal factors, this study sought to determine the contribution, if any, of the use of specific pharmaceuticals for depression, anxiety, or mood stabilization to the risk of obesity among adult survivors of childhood cancer. Additionally, we used structural equation modeling (SEM) to identify factors that directly predict, moderate, or mediate obesity to inform interventions for long-term health management.

\section{PATIENTS AND METHODS}

A cohort of 20,720 previously untreated patients who were less than 21 years of age at diagnosis, survived for at least 5 years after the date of diagnosis, and were diagnosed with an eligible cancer between January 1, 1970, and December 31, 1986 , was identified at the 26 participating institutions of the CCSS. This study was approved by the institutional review board at each participating institution. The study design, cohort characteristics, and baseline and follow-up data collection are presented in detail elsewhere. ${ }^{22-24}$ Data from survivors who completed the baseline and follow-up 2003 questionnaires and who were older than 18 years at the time of the follow-up 2003 questionnaire were eligible for this analysis. A total of 1,842 of those who were sent the follow-up 2003 questionnaire received a shortened version of the questionnaire from which the four pages of psychological outcome measures had been deleted.

The current report is based on data from both the baseline (used to determine only baseline frequency of aerobic exercise, defined as the number of days [0 to 7] on which exercise sufficient to induce sweating or breathing hard, lasting $\geq 20$ minutes, was performed ${ }^{25}$ ) and the 2003 follow-up questionnaire (used for ascertainment of all other data used in these analyses). Two previous CCSS reports on obesity used only data from the CCSS baseline questionnaire that were obtained between 1995 and 1996. ${ }^{1,26}$ A more recent CCSS publication, restricted to CCSS participants diagnosed with acute lymphoblastic leukemia, used the follow-up 2003 data but evaluated only different categories of cranial irradiation and treatment that included chemotherapy as a dichotomous variable. ${ }^{2}$

\section{Methods}

The primary outcome of interest was BMI, which was calculated using the standard formula — weight $(\mathrm{kg}) /(\text { height }[\mathrm{m}])^{2}$ — based on self-reported weight and height in the follow-up 2003 survey. Individuals were classified as obese if their BMI was $\geq 30 \mathrm{~kg} / \mathrm{m}^{2} .{ }^{27}$ Self-reported body weight was adjusted for those with amputated extremities by the following percentages: amputation of foot, $-1.5 \%$; below-the-knee amputation, $-3.7 \%$; knee disarticulation, $-5.7 \%$; Van Ness rotationplasty, $-7.2 \%$; above-the-knee amputation, $-11.0 \%$; hip disarticulation or hemipelvectomy, $-16.0 \%{ }^{28}$

Pharmaceutical use was assessed by the participant's response to the question, "Please indicate all medicines/drugs you took regularly during the two-year period between September 1, 2000 and September 1, 2002. We are only asking about medicines/drugs which you took consistently for more than one month, or for 30 days or more in a year " in several categories, including, "Antidepressants or other prescribed drugs for depression or other mood disorders such as Elavil, Prozac, Paxil, Zoloft, Navane, Ritalin or others," and "Other prescribed drugs." The specific pharmaceuticals evaluated included sertraline, paroxetine, fluoxetine (Prozac; Eli Lilly), citalopram (Celexa; Forest Laboratories, New York, NY), escitalopram (Lexapro; Forest Laboratories), 


\begin{tabular}{|c|c|c|c|}
\hline Variable & $\begin{array}{l}\text { No. of Obese } \\
\text { Participants }\end{array}$ & $\mathrm{RR}$ & $95 \% \mathrm{Cl}$ \\
\hline \multicolumn{4}{|l|}{ Sex } \\
\hline Male & 935 & 1.00 & \\
\hline Female & 972 & 1.07 & 0.99 to 1.16 \\
\hline \multicolumn{4}{|l|}{ Race/ethnicity } \\
\hline Non-Hispanic white & 1,662 & 1.00 & \\
\hline Non-Hispanic black & 86 & 1.35 & 1.12 to 1.62 \\
\hline Hispanic & 105 & 1.33 & 1.12 to 1.57 \\
\hline Other & 48 & 0.94 & 0.73 to 1.21 \\
\hline \multicolumn{4}{|l|}{ Age at questionnaire, years } \\
\hline $18-25$ & 418 & 1.00 & \\
\hline $26-35$ & 884 & 1.29 & 1.16 to 1.43 \\
\hline $36-45$ & 533 & 1.31 & 1.17 to 1.47 \\
\hline $46-55$ & 72 & 1.29 & 1.03 to 1.61 \\
\hline \multicolumn{4}{|l|}{ Education level } \\
\hline No high school or GED & 98 & 1.00 & \\
\hline High school or GED & 547 & 1.07 & 0.89 to 1.29 \\
\hline Some college no bachelor's degree & 621 & 0.92 & 0.77 to 1.11 \\
\hline Bachelor's degree or higher & 626 & 0.61 & 0.51 to 0.74 \\
\hline \multicolumn{4}{|l|}{ Age at diagnosis, years } \\
\hline $0-4$ & 706 & 1.00 & \\
\hline $5-9$ & 473 & 1.09 & 0.97 to 1.22 \\
\hline $10-14$ & 404 & 0.97 & 0.85 to 1.10 \\
\hline $15-20$ & 278 & 0.85 & 0.72 to 1.01 \\
\hline \multicolumn{4}{|l|}{ Family income } \\
\hline$<\$ 20,000 /$ year & 265 & 1.00 & \\
\hline$\geq \$ 20,000,<\$ 40,000 /$ year & 450 & 0.93 & 0.82 to 1.06 \\
\hline$\geq \$ 40,000 /$ year & 910 & 0.68 & 0.60 to 0.77 \\
\hline \multicolumn{4}{|l|}{ Health insurance } \\
\hline No & 237 & 1.00 & \\
\hline Yes or Canadian & 1,654 & 0.93 & 0.83 to 1.05 \\
\hline Baseline frequency of aerobic exercise* & 1,754 & 0.95 & 0.93 to 0.96 \\
\hline \multicolumn{4}{|l|}{ Physical activity } \\
\hline No & 1,502 & 1.00 & \\
\hline Yes & 377 & 0.65 & 0.59 to 0.72 \\
\hline \multicolumn{4}{|l|}{ Inactive lifestyle } \\
\hline Yes & 533 & 1.00 & \\
\hline No & 1,371 & 0.76 & 0.70 to 0.83 \\
\hline \multicolumn{4}{|l|}{ Hypothalamic/pituitary radiation } \\
\hline None & 554 & 1.00 & \\
\hline$<20 \mathrm{~Gy}$ & 652 & 0.94 & 0.84 to 1.04 \\
\hline $20-30 \mathrm{~Gy}$ & 318 & 1.48 & 1.31 to 1.66 \\
\hline$>30 \mathrm{~Gy}$ & 181 & 1.28 & 1.11 to 1.49 \\
\hline \multicolumn{4}{|l|}{ BSI-18 Depression Score } \\
\hline$<63$ & 1,383 & 1.00 & \\
\hline$\geq 63$ & 206 & 1.13 & 0.99 to 1.28 \\
\hline \multicolumn{4}{|l|}{ BSI-18 Somatic Distress Score } \\
\hline$<63$ & 1,308 & 1.00 & \\
\hline$\geq 63$ & 279 & 1.30 & 1.16 to 1.45 \\
\hline \multicolumn{4}{|l|}{ BSI-18 Anxiety Score } \\
\hline$<63$ & 1,462 & 1.00 & \\
\hline$\geq 63$ & 126 & 1.02 & 0.87 to 1.20 \\
\hline \multicolumn{4}{|l|}{ Cancer-related anxiety } \\
\hline 1: None & 1,023 & 1.00 & \\
\hline 2: Small amount & 388 & 0.85 & 0.76 to 0.94 \\
\hline 3: Medium amount & 123 & 0.91 & 0.77 to 1.08 \\
\hline 4: A lot & 41 & 0.94 & 0.71 to 1.23 \\
\hline 5: Very many, extreme & 14 & 0.97 & 0.61 to 1.54 \\
\hline \multicolumn{4}{|c|}{ (continued in next column) } \\
\hline
\end{tabular}

\begin{tabular}{|c|c|c|c|}
\hline Variable & $\begin{array}{l}\text { No. of Obese } \\
\text { Participants }\end{array}$ & $\mathrm{RR}$ & $95 \% \mathrm{Cl}$ \\
\hline \multicolumn{4}{|l|}{ Cancer-related pain } \\
\hline 1: None & 1,173 & 1.00 & \\
\hline 2: Small amount & 202 & 1.03 & 0.90 to 1.17 \\
\hline 3: Medium amount & 118 & 1.11 & 0.94 to 1.31 \\
\hline 4: A lot & 58 & 1.42 & 1.14 to 1.77 \\
\hline 5: Very bad, excruciating & 25 & 1.65 & 1.20 to 2.26 \\
\hline \multicolumn{4}{|l|}{ SF-36 Physical Function } \\
\hline$>40$ & 8,210 & 1.00 & \\
\hline$\leq 40$ & 1,027 & 1.53 & 1.38 to 1.70 \\
\hline \multicolumn{4}{|l|}{ Fluoxetine } \\
\hline No & 1,824 & 1.00 & \\
\hline Yes & 52 & 1.12 & 0.88 to 1.42 \\
\hline \multicolumn{4}{|l|}{ Sertraline } \\
\hline No & 1,794 & 1.00 & \\
\hline Yes & 82 & 1.26 & 1.04 to 1.52 \\
\hline \multicolumn{4}{|l|}{ Paroxetine } \\
\hline No & 1,804 & 1.00 & \\
\hline Yes & 72 & 1.40 & 1.15 to 1.71 \\
\hline \multicolumn{4}{|l|}{ Citalopram } \\
\hline No & 1,848 & 1.00 & \\
\hline Yes & 28 & 0.76 & 0.54 to 1.07 \\
\hline \multicolumn{4}{|l|}{ Escitalopram } \\
\hline No & 1,857 & 1.00 & \\
\hline Yes & 19 & 1.05 & 0.71 to 1.57 \\
\hline \multicolumn{4}{|l|}{ Bupropion } \\
\hline No & 1,832 & 1.00 & \\
\hline Yes & 44 & 1.29 & 1.00 to 1.66 \\
\hline \multicolumn{4}{|l|}{ Venlafaxine } \\
\hline No & 1,836 & 1.00 & \\
\hline Yes & 40 & 1.17 & 0.89 to 1.55 \\
\hline \multicolumn{4}{|l|}{ Amitriptyline } \\
\hline No & 1,870 & 1.00 & \\
\hline Yes & 6 & 0.93 & 0.45 to 1.89 \\
\hline \multicolumn{4}{|l|}{ Risperidone } \\
\hline No & 1,860 & 1.00 & \\
\hline Yes & 16 & 1.98 & 1.36 to 2.89 \\
\hline \multicolumn{4}{|l|}{ Valproate } \\
\hline No & 1,849 & 1.00 & \\
\hline Yes & 27 & 1.44 & 1.05 to 1.97 \\
\hline \multicolumn{4}{|c|}{$\begin{array}{l}\text { NOTE. Boldface indicates decreased risk of obesity. Italics indicates in- } \\
\text { creased risk of obesity. } \\
\text { Abbreviations: BSI-18, Brief Symptom Inventory-18; GED, general education } \\
\text { degree; RR, relative risk; SF-36, Short Form-36. } \\
\text { "Baseline frequency of aerobic exercise included as a continuous variable. }\end{array}$} \\
\hline
\end{tabular}

bupropion (Wellbutrin; GlaxoSmithKline), venlafaxine (Effexor; Pfizer Inc), amitriptyline (Elavil; AstraZeneca UK Limited, London, United Kingdom), risperidone, and sodium valproate. Drugs used by fewer than 30 patients including quetiapine (Seroquel; AstraZeneca Pharmaceuticals LP, Wilmington, DE), clozapine (Clozaril; Novartis Pharmaceuticals), desipramine (Norpramin; sanofi-aventis US LLC, Bridgewater, NJ), nortriptyline (Pamelor; Mallinckrodt Inc, St Louis, MO), ziprasidone (Geodon; Pfizer), thioridazine (Mellaril; Novartis Pharmaceuticals), aripiprazole (Abilify; Otsuka America Pharmaceutical Inc, Rockville, MD), olanzapine, doxepin (Sinequan; Pfizer), imipramine (Tofranil; Ciba-Geigy AG, Basel, Switzerland), and nefazodone (Serzone; Bristol-Myers Squibb, Princeton, NJ) were not included in the univariable or multivariable regression analyses or the SEM analysis.

Additional independent variables included demographics, treatment exposures, baseline frequency of aerobic exercise, ${ }^{25}$ physical activity, physical 
function, intrapersonal factors, cancer-related pain, and cancer-related anxiety/fears. Radiation dose to the hypothalamic/pituitary region was estimated for each patient $\mathrm{t}^{29,30}$ as previously described by Stovall et al. ${ }^{31,32}$

Patients were classified as physically active if they indicated that they satisfied the US Centers for Disease Control and Prevention (CDC) guidelines for physical activity (30 minutes of moderate-intensity physical activity on $\geq 5$ days of the week or 20 minutes of vigorous intensity physical activity on $\geq 3$ days of the week). ${ }^{33}$ Patients were classified as inactive if they reported no participation in any leisure-time physical activity over the past month $(1=$ active; 0 = inactive). Physical function was categorized on the basis of participant scores on the physical function subscale of the Short Form-36 (SF-36), with a score $\leq 40$ indicating abnormal physical function. ${ }^{34,35}$

Intrapersonal factors were quantified using the scores on the BSI subscales of depression, somatic distress, and anxiety. Cancer-related pain was quantified using a 5 -point scale ( $1=$ no pain; $5=$ very bad, excruciating pain $)$. Cancer-related anxiety/fears was quantified using a 5 -point scale $(1=$ no anxiety/fears; $5=$ very many, extreme anxiety/fears).

\section{Statistical Analysis}

Univariate log-binomial regression analysis was applied to evaluate the effect of demographic, treatment, lifestyle, intrapersonal, and pharmaceutical usage variables on the relative risk of obesity. ${ }^{36,37}$ Covariates with $P<.1$ in the univariate analysis were selected for the multivariable model and were further reduced on the basis of the likelihood ratio statistics for type III contrasts. ${ }^{38}$ Age at questionnaire, sex, and race/ethnicity were forced into both univariate and multivariable models. The data analysis was performed on SAS 9.1 (SAS Institute, Cary, NC).

\section{SEM Measures}

Observed and latent variables were modeled in SEM. Factorial validity of the latent variables was established through exploratory and confirmatory factor analyses. The latent variables in the SEM included depression (defined by four of six items from the $\mathrm{BSI}^{39,40}$ : lonely, blue, no interest, hopeless) and physical function (defined by five of 10 items from the physical function subscale of the SF- $36^{41,42}$ : climb several stairs, climb one flight of stairs, walk several miles, walk several blocks, walk one block). The conceptually sound, best-fitting model was based on established SEM fit criteria (a root mean square error of approximation [RMSEA] $\leq 0.05,{ }^{43,44}$ comparative fit index $[\mathrm{CFI}]$ and Tucker Lewis index $[\mathrm{TLI}] \geq 0.90,{ }^{45}$ and a weighted root mean square residual [WRMR] less than $0.90^{46}$ when the outcome variable was binary).

SEM was analyzed using Mplus 6.1 software. ${ }^{47}$ To model the mediators and moderators in SEM, a sub-program, INDIRECT, was used. The significance of the mediator or moderator was determined by the strength of the estimate, divided by the SE.

\section{RESULTS}

\section{Study Population}

Nine thousand two hundred eighty-four survivors who were $\geq 18$ years of age at the time of completion of the follow-up 2003 questionnaire were included in these analyses (Table 1). Slightly more than half of the study population was male, and participants were predominantly white. Most had at least a high school diploma or equivalent. More than $60 \%$ were diagnosed when younger than age 10 years, and nearly $30 \%$ were older than age 35 years at the time of evaluation. Approximately 13\% of survivors had annual household incomes of less than $\$ 25,000$ per year. Almost $90 \%$ had health insurance or were Canadian residents. Radiation to the hypothalamicpituitary axis was part of treatment for more than $60 \%$ of survivors.

Antidepressant use was reported by $13.8 \%$ of survivors overall. Of those who used an antidepressant, $77.4 \%$ reported the use of only a single antidepressant during the 2 -year period. Fluoxetine, sertraline, and paroxetine were the most commonly used of this class of drugs.

\begin{tabular}{|c|c|c|}
\hline Variable & $\mathrm{RR}$ & $95 \% \mathrm{Cl}$ \\
\hline \multicolumn{3}{|l|}{ Sex } \\
\hline Male & 1.00 & \\
\hline Female & 1.02 & 0.95 to 1.09 \\
\hline \multicolumn{3}{|l|}{ Race/ethnicity } \\
\hline Non-Hispanic white & 1.00 & \\
\hline Non-Hispanic black & 1.10 & 0.88 to 1.36 \\
\hline Hispanic & 1.12 & 0.93 to 1.33 \\
\hline Other & 0.84 & 0.65 to 1.10 \\
\hline \multicolumn{3}{|l|}{ Age at questionnaire, years } \\
\hline $18-25$ & 1.00 & \\
\hline $26-35$ & 1.11 & 1.00 to 1.24 \\
\hline $36-45$ & 1.13 & 0.98 to 1.30 \\
\hline $46-55$ & 1.19 & 0.95 to 1.51 \\
\hline \multicolumn{3}{|l|}{ Education level } \\
\hline No high school or GED & 1.00 & \\
\hline High school or GED & 1.03 & 0.85 to 1.26 \\
\hline Some college no bachelor's degree & 1.00 & 0.82 to 1.21 \\
\hline Bachelor's degree or higher & 0.85 & 0.70 to 1.03 \\
\hline \multicolumn{3}{|l|}{ Age at diagnosis, years } \\
\hline $0-4$ & 1.00 & \\
\hline 5-9 & 1.12 & 1.01 to 1.24 \\
\hline $10-14$ & 1.06 & 0.94 to 1.19 \\
\hline $15-20$ & 1.04 & 0.90 to 1.20 \\
\hline \multicolumn{3}{|l|}{ Family income } \\
\hline$<\$ 20,000 /$ year & 1.00 & \\
\hline$\geq \$ 20,000,<\$ 40,000 /$ year & 1.08 & 0.96 to 1.22 \\
\hline$\geq \$ 40,000 /$ year & 0.95 & 0.85 to 1.07 \\
\hline Baseline frequency of aerobic exercise* & 0.99 & 0.97 to 1.00 \\
\hline \multicolumn{3}{|l|}{ Physical activity } \\
\hline No & 1.00 & \\
\hline Yes & 0.90 & 0.82 to 0.97 \\
\hline \multicolumn{3}{|l|}{ Hypothalamic/pituitary radiation } \\
\hline None & 1.00 & \\
\hline$<20 \mathrm{~Gy}$ & 0.94 & 0.86 to 1.02 \\
\hline 20-30 Gy & 1.17 & 1.05 to 1.30 \\
\hline$>30 \mathrm{~Gy}$ & 1.00 & 0.87 to 1.15 \\
\hline \multicolumn{3}{|l|}{ BSI-18 Somatic Distress Score } \\
\hline$<63$ & 1.00 & \\
\hline$\geq 63$ & 1.04 & 0.94 to 1.16 \\
\hline \multicolumn{3}{|l|}{ Cancer-related anxiety } \\
\hline None & 1.00 & \\
\hline Small amount & 0.94 & 0.87 to 1.02 \\
\hline Medium amount & 0.86 & 0.75 to 0.99 \\
\hline A lot & 0.85 & 0.67 to 1.08 \\
\hline Very many, extreme & 0.76 & 0.50 to 1.17 \\
\hline \multicolumn{3}{|l|}{ SF-36 Physical Function } \\
\hline$>40$ & 1.00 & \\
\hline$\leq 40$ & 1.19 & 1.06 to 1.33 \\
\hline \multicolumn{3}{|l|}{ Paroxetine } \\
\hline No & 1.00 & \\
\hline Yes & 1.29 & 1.08 to 1.54 \\
\hline \multicolumn{3}{|l|}{ Bupropion } \\
\hline No & 1.00 & \\
\hline Yes & 1.15 & 0.91 to 1.47 \\
\hline \multicolumn{3}{|l|}{ Risperidone } \\
\hline No & 1.00 & \\
\hline Yes & 1.32 & 0.88 to 1.98 \\
\hline \multicolumn{3}{|l|}{ Sertraline } \\
\hline No & 1.00 & \\
\hline Yes & 1.08 & 0.91 to 1.30 \\
\hline \multicolumn{3}{|c|}{$\begin{array}{l}\text { NOTE. Boldface indicates decreased risk of obesity. Italics indicates in- } \\
\text { creased risk of obesity. } \\
\text { Abbreviations: BSI-18, Brief Symptom Inventory-18; GED, general education } \\
\text { degree; RR, relative risk; SF-36, Short Form-36. } \\
\text { "Baseline frequency of aerobic exercise included as a continuous variable. }\end{array}$} \\
\hline
\end{tabular}


Risk Factors for Obesity in Adult Survivors of Childhood Cancer

\begin{tabular}{|c|c|c|c|c|}
\hline Factor & Estimate & SE & Estimate/SE & $P$ \\
\hline \multicolumn{5}{|l|}{ Obesity } \\
\hline Physical function* & -0.098 & 0.013 & -7.407 & $<.001$ \\
\hline Cancer-related anxiety & -0.127 & 0.027 & -4.748 & $<.001$ \\
\hline Education level & -0.068 & 0.020 & -3.336 & .001 \\
\hline Physical activity & -0.067 & 0.024 & -2.842 & .004 \\
\hline Age at questionnaire & 0.007 & 0.002 & 2.791 & .005 \\
\hline Hypothalamic/pituitary radiation & 0.049 & 0.018 & 2.707 & .007 \\
\hline Family income & -0.055 & 0.022 & -2.490 & .013 \\
\hline Paroxetine & 0.081 & 0.041 & 1.972 & .049 \\
\hline \multicolumn{5}{|l|}{ Physical function* } \\
\hline Cancer-related pain & -0.964 & 0.063 & -15.253 & $<.001$ \\
\hline Gender & -0.711 & 0.073 & -9.683 & $<.001$ \\
\hline Inactive lifestyle & 0.925 & 0.096 & 9.613 & $<.001$ \\
\hline Education level & 0.376 & 0.041 & 9.246 & $<.001$ \\
\hline Age at questionnaire & -0.037 & 0.005 & -8.001 & $<.001$ \\
\hline Hypothalamic/pituitary radiation & -0.171 & 0.035 & -4.878 & $<.001$ \\
\hline Cancer-related anxiety & -0.136 & 0.042 & -3.227 & .001 \\
\hline \multicolumn{5}{|l|}{ Cancer-related anxiety } \\
\hline Sex & 0.238 & 0.029 & 8.164 & $<.001$ \\
\hline Age at questionnaire & 0.008 & 0.002 & 4.198 & $<.001$ \\
\hline \multicolumn{5}{|l|}{ Cancer-related pain } \\
\hline Cancer-related anxiety & 0.465 & 0.021 & 22.629 & $<.001$ \\
\hline Age at questionnaire & 0.021 & 0.002 & 8.911 & $<.001$ \\
\hline Education level & -0.144 & 0.021 & -6.993 & $<.001$ \\
\hline Physical activity & -0.083 & 0.023 & -3.607 & $<.001$ \\
\hline Baseline frequency of aerobic exercise & -0.062 & 0.020 & -3.115 & .002 \\
\hline \multicolumn{5}{|l|}{ Baseline frequency of aerobic exercise } \\
\hline Age at questionnaire & -0.031 & 0.002 & -20.136 & $<.001$ \\
\hline Sex & -0.287 & 0.023 & -12.218 & $<.001$ \\
\hline Hypothalamic/pituitary radiation & -0.089 & 0.013 & -6.850 & $<.001$ \\
\hline Education level & 0.065 & 0.013 & 4.946 & $<.001$ \\
\hline \multicolumn{5}{|l|}{ Inactive lifestyle } \\
\hline Education level & 0.070 & 0.008 & 9.145 & $<.001$ \\
\hline Baseline frequency of aerobic exercise & 0.148 & 0.021 & 6.950 & $<.001$ \\
\hline Hypothalamic/pituitary radiation & -0.013 & 0.005 & -2.513 & .012 \\
\hline \multicolumn{5}{|l|}{ Physical activity } \\
\hline Baseline frequency of aerobic exercise & 0.288 & 0.017 & 17.206 & $<0.001$ \\
\hline Education level & 0.138 & 0.018 & 7.704 & $<.001$ \\
\hline Sex & 0.223 & 0.031 & 7.283 & $<.001$ \\
\hline Hypothalamic/pituitary radiation & -0.092 & 0.018 & -5.125 & $<.001$ \\
\hline Age at questionnaire & -0.005 & 0.002 & -2.579 & .010 \\
\hline \multicolumn{5}{|l|}{ Family income } \\
\hline Education level & 0.285 & 0.017 & 16.632 & $<.001$ \\
\hline Age at questionnaire & 0.026 & 0.002 & 12.521 & $<.001$ \\
\hline Hypothalamic/pituitary radiation & -0.146 & 0.016 & -9.110 & $<.001$ \\
\hline Cancer-related pain & -0.124 & 0.019 & -6.509 & $<.001$ \\
\hline Sex & -0.125 & 0.030 & -4.113 & $<.001$ \\
\hline Inactive lifestyle & 0.161 & 0.042 & 3.782 & $<.001$ \\
\hline Physical activity & 0.067 & 0.023 & 2.957 & .003 \\
\hline \multicolumn{5}{|l|}{ Paroxetine } \\
\hline Cancer-related anxiety & 0.303 & 0.036 & 8.440 & $<.001$ \\
\hline Sex & 0.253 & 0.062 & 4.105 & $<.001$ \\
\hline Education level & -0.128 & 0.032 & -3.955 & $<.001$ \\
\hline
\end{tabular}


Poor physical function was present in $11.12 \%$ of survivors. Only $27.99 \%$ met the CDC guidelines for physical activity; $22.79 \%$ reported no physical activity over the past month. Using the BSI outcome, nearly $12 \%$ of survivors were depressed, $13.94 \%$ had somatic distress, and $7.80 \%$ had anxiety. More than $38 \%$ of the survivors reported some degree of cancer-related anxiety, and almost $23 \%$ reported some cancer-related pain.

\section{Univariate and Multivariable Analyses}

The results of univariate analyses to identify factors associated with obesity are shown in Table 2 . Factors associated with an increased risk of obesity $\left(\mathrm{BMI}>30 \mathrm{~kg} / \mathrm{m}^{2}\right)$ included Hispanic or non-Hispanic; black race/ethnicity; age at questionnaire of older than 25 years; hypothalamic/pituitary radiation dose exceeding 20 Gy; BSI-18 somatic distress score $\geq 63$; a lot of or very bad, excruciating cancer-related pain; poor physical function based on the SF-36 score $\leq 40$; and treatment with sertraline, paroxetine, risperidone, or valproate. Factors that decreased the risk of obesity included a bachelor's degree or higher educational attainment, family income $\geq \$ 40,000 /$ year, baseline frequency of aerobic exercise, meeting the CDC guidelines for physical activity, participation in any leisure-time physical activity over the past month, and a small amount of cancer-related anxiety/fears.

Factors that remained significant in the multivariable model are shown in Table 3. The risk of obesity was increased among those 5 to 9 years of age at diagnosis $(\mathrm{RR}=1.12 ; 95 \% \mathrm{CI}, 1.01$ to $1.24 ; P=.03)$, those who received 20 to $30 \mathrm{~Gy}$ of hypothalamic/pituitary radiation dose $(\mathrm{RR}=1.17 ; 95 \% \mathrm{CI}, 1.05$ to $1.30 ; P=.01)$, and those with abnormal SF-36 physical function ( $R R=1.19 ; 95 \%$ CI, 1.06 to 1.33 ; $P<.001)$. The risk of obesity was decreased among those who met the CDC guidelines for physical activity $(\mathrm{RR}=0.90 ; 95 \% \mathrm{CI}, 0.82$ to 0.97 ; $P=.01)$ and among those with a medium amount of cancer-related anxiety $(\mathrm{RR}=0.86 ; 95 \% \mathrm{CI}, 0.75$ to $0.99 ; P=.04)$. Of the pharmaceuticals evaluated, only paroxetine was independently associated with an increased risk for obesity $(\mathrm{RR}=1.29 ; 95 \% \mathrm{CI}, 1.08$ to $1.54 ; P=.01)$.

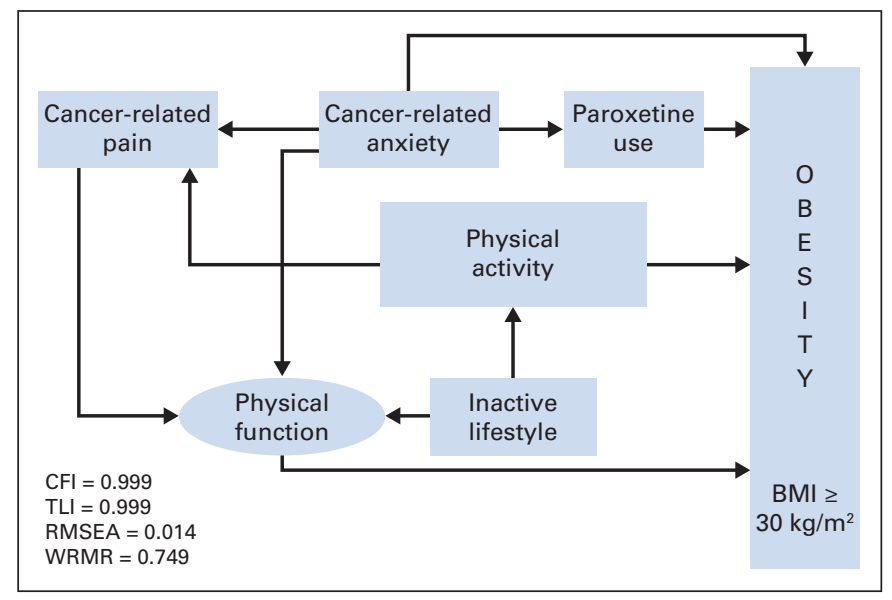

Fig 1. Direct and mediating influences on survivor obesity. Latent variables are illustrated as ellipses, and directly observed variables are illustrated as rectangles. $\mathrm{BMI}$, body mass index; CFI, comparative fit index; TLI, Tucker Lewis index; RMSEA, root mean square error of approximation; WRMR, weighted root mean square residual.

\section{SEM Analysis}

All of the significant variables and their contributions to the model are shown in Table 4. A simplified graphic version of the complete SEM results is shown in Figure 1. A well-fitting model $(\mathrm{N}=8,244 ; \mathrm{CFI}=0.999 ; \mathrm{TLI}=0.999 ; \mathrm{RMSEA}=0.014$; WRMR $=0.749$ ) identified the complex interrelationships among the directly observed and latent variables that influence obesity in adult survivors of childhood cancer.

Poor physical function was the strongest direct predictor of obesity, followed by lower self-reported cancer-related anxiety, less education, not meeting CDC guidelines for physical activity, older age at questionnaire, hypothalamic/pituitary radiation exposure, lower family income, and paroxetine use (Table 4). Analysis of potential moderators and mediators of obesity demonstrated significance for cancer-related pain through physical function $(\mathrm{EST} / \mathrm{SE}=7.714$, $P \leq .001$ ), cancer-related anxiety through physical function (EST/ $\mathrm{SE}=2.986, P=.003)$, and cancer-related anxiety through cancerrelated pain and physical function $(\mathrm{EST} / \mathrm{SE}=7.279, P \leq .001)$. Not meeting CDC guidelines for recommended physical activity mediated obesity through cancer-related pain and physical function (EST/ $\mathrm{SE}=-3.411, P=.001)$.

\section{DISCUSSION}

In the general population, obesity is associated with increased morbidity and mortality. ${ }^{48}$ The adverse health implications of obesity may be greater among childhood cancer survivors whose exposures place them at an increased risk for severe and life-threatening chronic health conditions. ${ }^{49}$ Understanding the factors that contribute to obesity in childhood cancer survivors, either directly or as mediators and moderators, can facilitate clinical management. Greater insight into the predictors of obesity will facilitate design and evaluation of innovative intervention/prevention strategies targeting childhood cancer survivors.

Using two different, but complementary, analytic approaches, this study evaluated the risk factors associated with obesity among adult survivors of childhood cancer who participated in the CCSS. The results of the multivariable model demonstrated that impaired physical function, hypothalamic-pituitary radiation, use of paroxetine, and younger age at cancer diagnosis were statistically significant independent predictors for a $\mathrm{BMI} \geq 30 \mathrm{~kg} / \mathrm{m}^{2}$. Meeting CDC guidelines for physical activity and a moderate amount of anxiety decreased the risk for a BMI $\geq 30 \mathrm{~kg} / \mathrm{m}^{2}$.

SEM provided similar findings, while indicating that the impact of physical function on obesity was mediated by cancerrelated anxiety, cancer-related pain, and an inactive lifestyle. The primary differences in findings between the two approaches relate to education level, age at questionnaire, and family income, where SEM identified a direct association with obesity, but no statistically significant associations were evident in the multivariable model. It is not immediately apparent why these differences exist. Possible explanations include the formulation of some variables in the SEM as continuous variables (eg, age at questionnaire) that were analyzed as categorical variables in the multivariable model. In addition, latent variables derived in the SEM (eg, physical function), 
though based on the SF-36, are not the same variable as the dichotomized variable used in the multivariable analysis that was based on the entire SF-36 Physical Function score.

The association between obesity, the use of specific pharmaceuticals, and their relationship with cancer-related anxiety, cancerrelated pain, physical activity, and physical function are novel findings. The use of antidepressants has increased dramatically in the 18- to 44-year age group during the period 1992 to 2002, along with a significant shift from prescribing tricyclic antidepressants to selective serotonin reuptake inhibitors. ${ }^{50}$ Weight gain is a frequent adverse effect of the use of some antidepressant and antipsychotic drugs. ${ }^{5-18}$ Among the drugs used for seizure control, weight gain is increased among patients treated with sodium valproate compared with carbamazepine (Tegretol; Novartis Pharmaceuticals). ${ }^{19-21}$

We identified the use of a specific antidepressant, paroxetine (Paxil), as a risk factor associated with obesity in adult survivors of childhood cancer in the multivariable model and as a direct predictor of obesity in the SEM. We lack longitudinal data, particularly BMI data, before the initiation of antidepressant therapy. Therefore, we cannot determine whether obesity, possibly caused by prior treatment, such as cranial irradiation, resulted in depression that was then treated with an antidepressant or whether depression in a nonobese CCSS participant treated with an antidepressant resulted in the development of obesity. A longitudinal study is needed to address these questions. In addition, we lack data on calorie intake and therefore cannot evaluate the relationship of this important determinant of energy balance to the risk of obesity in our population.

An additional unique finding of this analysis was poor physical function as a direct predictor of obesity. Poor physical function was predicted by female sex, older current age, having less education, having been exposed to hypothalamic/pituitary radiation, increased cancer-related pain and anxiety, and leisure-time physical inactivity. Increased physical performance limitations and decreased ability to do routine activities have been documented in adult childhood cancer survivors, ${ }^{51}$ but their link to obesity has not been established. Diminished functional performance and disability have been linked to obesity, however, in the general population. ${ }^{52-54}$

Increased cancer-related anxiety/fears predicted nonobesity in the present study; previous studies have documented that underweight survivors were more likely to report adverse health and major medical conditions. ${ }^{1}$ Correspondingly, those who are most worried about their cancer are those who also report more late effects and related symptoms. ${ }^{25}$ Cancer-related anxiety was also antecedent to paroxetine use; paroxetine is commonly prescribed for the treatment of anxiety.

Although the single item addressing cancer-related fears/anxiety was significant in the SEM, the BSI anxiety subscale was not. The BSI anxiety subscale assesses symptoms present over the past 7 days and likely reflects generalized acute or "state" anxiety; it does not measure nonpathologic specific anxiety/worry as does the single-item cancerrelated anxiety measure. Indeed, specific anxiety contributes to greater generalized anxiety, ${ }^{55}$ and we have illustrated this relationship in previous reports. ${ }^{25}$ Cancer-specific anxiety may well exacerbate state anxiety symptoms, but is conceptually and, in this case analytically, distinct from the BSI.

Cranial radiation is a well-established risk factor for obesity among adult survivors of ALL., ${ }^{26}$ Cranial radiation $\geq 10$ Gy was associated with a statistically significant mean BMI increase of 0.41 $\mathrm{kg} / \mathrm{m}^{2} /$ year among female survivors and $0.29 \mathrm{~kg} / \mathrm{m}^{2} /$ year among male survivors, in comparison with siblings. ${ }^{2}$ In addition to the direct effect of hypothalamic/pituitary radiation exposure on obesity, the SEM identified radiation of hypothalamic/pituitary axis as a moderator of obesity through its negative impact on physical function, baseline exercise frequency, and leisure time physical activity.

Meeting CDC guidelines for regular physical activity was associated with a lower risk of obesity in both the multivariable analysis and in the SEM. Previous data from the CCSS indicated that male and female survivors with all diagnoses were more likely to lead an inactive lifestyle compared with CCSS sibling participants. Only male survivors with the diagnoses of other CNS tumor or HL and female survivors with the diagnoses of acute myeloid leukemia, other or unspecified leukemia, HL, kidney tumor, or Ewing sarcoma met the CDC physical activity guidelines. ${ }^{56}$

In conclusion, this study identified previously unreported factors that are associated with obesity in adult survivors of childhood cancer. The use of specific pharmaceuticals to address anxiety and depression and their relationship with cancer-related pain, decreased physical activity, and physical function have not been reported previously. Important mediators and moderators of obesity help to identify more accurately those who are at risk for obesity and potentially suggest novel strategies (eg, distancedelivered interventions that specifically target anxiety, motivation, and strategies for behavior change) that may be investigated in patients during and after pediatric cancer therapy to diminish their risk for post-therapy obesity.

\section{AUTHORS' DISCLOSURES OF POTENTIAL CONFLICTS OF INTEREST}

Although all authors completed the disclosure declaration, the following author(s) indicated a financial or other interest that is relevant to the subject matter under consideration in this article. Certain relationships marked with a " $U$ " are those for which no compensation was received; those relationships marked with a " $C$ " were compensated. For a detailed description of the disclosure categories, or for more information about ASCO's conflict of interest policy, please refer to the Author Disclosure Declaration and the Disclosures of Potential Conflicts of Interest section in Information for Contributors.

Employment or Leadership Position: None Consultant or Advisory Role: Leslie L. Robison, Eli Lilly (C) Stock Ownership: None Honoraria: None Research Funding: None Expert Testimony: None Other Remuneration: None

\section{AUTHOR CONTRIBUTIONS}

Conception and design: Daniel M. Green, Sarah S. Donaldson, Gregory T. Armstrong, Leslie L. Robison

Financial support: Leslie L. Robison

Provision of study materials or patients: Marilyn Stovall Collection and assembly of data: Marilyn Stovall, Kirsten K. Ness, Leslie L. Robison

Data analysis and interpretation: Daniel M. Green, Cheryl L. Cox, Liang Zhu, Kevin R. Krull, Deo Kumar Srivastava, Vikki G. Nolan, Kirsten K. Ness, Kevin C. Oeffinger, Lillian R. Meacham, Charles A. Sklar, Leslie L. Robison

Manuscript writing: All authors

Final approval of manuscript: All authors 


\section{REFERENCES}

1. Meacham LR, Gurney JG, Mertens AC, et al: Body mass index in long-term adult survivors of childhood cancer: A report of the Childhood Cancer Survivor Study. Cancer 103:1730-1739, 2005

2. Garmey EG, Liu Q, Sklar CA, et al: Longitudinal changes in obesity and body mass index among adult survivors of childhood acute lymphoblastic leukemia: A report from the Childhood Cancer Survivor Study. J Clin Oncol 26:4639-4645, 2008

3. Zebrack BJ, Zeltzer LK, Whitton J, et al: Psychological outcomes in long-term survivors of childhood leukemia, Hodgkin's disease, and nonHodgkin's lymphoma: A report from the Childhood Cancer Survivor Study. Pediatrics 110:42-52, 2002

4. Zebrack BJ, Zevon MA, Turk N, et al: Psychological distress in long-term survivors of solid tumors diagnosed in childhood: A report from the Childhood Cancer Survivor Study. Pediatr Blood Cancer 49:47-51, 2007

5. Fava M, Judge R, Hoog SL, et al: Fluoxetine versus sertraline and paroxetine in major depressive disorder: Changes in weight with long-term treatment. J Clin Psychiatry 61:863-867, 2000

6. Aberg-Wistedt $A$, Agren $H$, Ekselius $L$, et al: Sertraline versus paroxetine in major depression: Clinical outcome after six months of continuous therapy. J Clin Psychopharmacol 20:645-652, 2000

7. Saddichha S, Ameen S, Akhtar S: Predictors of antipsychotic-induced weight gain in first-episode psychosis: Conclusions from a randomized, doubleblind, controlled prospective study of olanzapine, risperidone, and haloperidol. J Clin Psychopharmacol 28:27-31, 2008

8. Safer DJ: A comparison of risperidoneinduced weight gain across the age span. J Clin Psychopharmacol 24:429-436, 2004

9. Tran PV, Hamilton SH, Kuntz AJ, et al: Doubleblind comparison of olanzapine versus risperidone in the treatment of schizophrenia and other psychotic disorders. J Clin Psychopharmacol 17:407-418, 1997

10. Basson BR, Kinon BJ, Taylor CC, et al: Factors influencing acute weight change in patients with schizophrenia treated with olanzapine, haloperidol, or risperidone. J Clin Psychiatry 62:231-238, 2001

11. Bustillo JR, Buchanan RW, Irish D, et al: Differential effect of clozapine on weight: A controlled study. Am J Psychiatry 153:817-819, 1996

12. Allison DB, Mentore JL, Heo $M$, et al: Antipsychotic-induced weight gain: A comprehensive research synthesis. Am J Psychiatry 156:16861696, 1999

13. McQuade RD, Stock E, Marcus $R$, et al: $A$ comparison of weight change during treatment with olanzapine or aripiprazole: Results from a randomized, double-blind study. J Clin Psychiatry 65:47-56, 2004

14. Kinon BJ, Lipkovich I, Edwards SB, et al: A 24-week randomized study of olanzapine versus ziprasidone in the treatment of schizophrenia or schizoaffective disorder in patients with prominen depressive symptoms. J Clin Psychopharmacol 26: 157-162, 2006

15. Daniel DG, Zimbroff DL, Potkin SG, et al: Ziprasidone $80 \mathrm{mg} /$ day and $160 \mathrm{mg} /$ day in the acute exacerbation of schizophrenia and schizoaffective disorder: A 6-week placebo-controlled trial-Ziprasidone Study Group. Neuropsychopharmacology 20:491-505, 1999

16. Arato M, O'Connor R, Meltzer HY: A 1-year, double-blind, placebo-controlled trial of ziprasidone 40, 80 and $160 \mathrm{mg} /$ day in chronic schizophrenia: The
Ziprasidone Extended Use in Schizophrenia (ZEUS) study. Int Clin Psychopharmacol 17:207-215, 2002

17. Small JG, Hirsch SR, Arvanitis LA, et al: Quetiapine in patients with schizophrenia. A high- and low-dose double-blind comparison with placebo Seroquel Study Group. Arch Gen Psychiatry 54:549557, 1997

18. Arvanitis LA, Miller BG: Multiple fixed doses of "Seroquel" (quetiapine) in patients with acute exacerbation of schizophrenia: A comparison with haloperidol and placebo-The Seroquel Trial 13 Study Group. Biol Psychiatry 42:233-246, 1997

19. Verity CM, Hosking G, Easter DJ: A multicentre comparative trial of sodium valproate and carbamazepine in paediatric epilepsy: The Paediatric EPITEG Collaborative Group. Dev Med Child Neurol 37:97-108, 1995

20. Richens A, Davidson DL, Cartlidge NE, et al: A multicentre comparative trial of sodium valproate and carbamazepine in adult onset epilepsy: Adult EPITEG Collaborative Group. J Neurol Neurosurg Psychiatry 57:682-687, 1994

21. Mattson RH, Cramer JA, Collins JF: A comparison of valproate with carbamazepine for the treatment of complex partial seizures and secondarily generalized tonic-clonic seizures in adults: The Department of Veterans Affairs Epilepsy Cooperative Study No. 264 Group. N Engl J Med 327:765771, 1992

22. Leisenring WM, Mertens AC, Armstrong GT et al: Pediatric cancer survivorship research: Experience of the Childhood Cancer Survivor Study. J Clin Oncol 27:2319-2327, 2009

23. Robison LL, Mertens AC, Boice JD, et al: Study design and cohort characteristics of the childhood cancer survivor study: A multi-institutional collaborative project. Med Pediatr Oncol 38:229239, 2002

24. Robison LL, Armstrong GT, Boice JD, et al: The Childhood Cancer Survivor Study: A National Cancer Institute-supported resource for outcome and intervention research. J Clin Oncol 27:23082318, 2009

25. Cox CL, Montgomery M, Oeffinger $\mathrm{KC}$, et al: Promoting physical activity in childhood cancer survivors: Results from the Childhood Cancer Survivor Study. Cancer 115:642-654, 2009

26. Oeffinger KC, Mertens AC, Sklar CA, et al: Obesity in adult survivors of childhood acute lymphoblastic leukemia: A report from the Childhood Cancer Survivor Study. J Clin Oncol 21:1359-1365, 2003

27. National Heart, Lung and Blood Institute Expert Panel on the Identification, Evaluation and Treatment of Overweight and Obesity in Adults: Clinical Guidelines on the Identification, Evaluation and Treatment of Overweight and Obesity in Adults. Bethesda, MD, National Institutes of Health, 1998

28. Osterkamp LK: Current perspective on assessment of human body proportions of relevance to amputees. J Am Diet Assoc 95:215-218, 1995

29. Packer RJ, Gurney JG, Punyko JA, et al: Long-term neurologic and neurosensory sequelae in adult survivors of a childhood brain tumor: Childhood Cancer Survivor Study. J Clin Oncol 21:3255-3261, 2003

30. Green DM, Kawashima $T$, Stovall $M$, et al: Fertility of female survivors of childhood cancer: A report from the Childhood Cancer Survivor Study. J Clin Oncol 27:2677-2685, 2009

31. Stovall M, Donaldson SS, Weathers RE, et al: Genetic effects of radiotherapy for childhood cancer: Gonadal dose reconstruction. Int J Radiat Oncol Biol Phys 60:542-552, 2004
32. Stovall M, Weathers R, Kasper $\mathrm{C}$, et al: Dose reconstruction for therapeutic and diagnostic radiation exposures: Use in epidemiological studies. Radiat Res 166:141-157, 2006

33. Physical Activity Guidelines Advisory Committee: Physical Activity Guidelines Advisory Committee Report, 2008. Washington, DC, Department of Health and Human Services, 2008

34. Zeltzer LK, Lu Q, Leisenring W, et al: Psychosocial outcomes and health-related quality of life in adult childhood cancer survivors: A report from the Childhood Cancer Survivor Study. Cancer Epidemiol Biomarkers Prev 17:435-446, 2008

35. Ware JE, Snow KK, Kosinski M. SF-36 Health Survey: Manual and Interpretation Guide. Lincoln, RI, Quality-Metric, 2000

36. Wacholder S: Binomial regression in GLIM: Estimating risk ratios and risk differences. Am J Epidemiol 123:174-184, 1986

37. Spiegelman D, Hertzmark E: Easy SAS calculations for risk or prevalence ratios and differences. Am J Epidemiol 162:199-200, 2005

38. Stokes ME, Davis CS, Koch GG: Categorical data analysis using the SAS system. Cary, NC, SAS Institute, 1995

39. Derogatis LR: Brief Symptom Inventory (BSI) 18: Administration, scoring, and procedures manual. Minneapolis, MN, NCS Pearson, 2000

40. Recklitis CJ, Parsons SK, Shih MC, et al: Factor structure of the Brief Symptom Inventory-18 in adult survivors of childhood cancer: Results from the Childhood Cancer Survivor Study. Psychol Assess 18:22-32, 2006

41. Ware JEJ, Sherbourne CD: The MOS 36-item short-form health survey (SF-36): I. Conceptual framework and item selection. Med Care 30:473483, 1992

42. McHorney CA, Ware JEJ, Raczek AE: The MOS 36-Item Short-Form Health Survey (SF-36): II. Psychometric and clinical tests of validity in measuring physical and mental health constructs. Med Care 31:247-263, 1993

43. Browne M, Cudeck, R: Alternative ways of assessing model fit, in Bollen KA, Long JA (eds): Testing Structural Equation Models. Newbury Park, CA, Sage, 1993, pp 136-162

44. Hu L, Bentler P: Cutoff criteria for fit indices in covariance structure analysis: Conventional criteria versus new alternatives. Struct Equ Modeling 6:1 55, 1999

45. Bollen K: Overall fit in covariance structure models: Two types of sample size effects. Psychol Bull 107:256-259, 1990

46. Yu CY, Muthe'n BO: Evaluation of model fit indices for latent variable models with categorical and continuous outcomes. Los Angeles, CA, UCLA, Graduate School of Education and Information Studies, 2002

47. Muto R, Yamamori S, Ohashi H, et al: Prediction by FISH analysis of the occurrence of Wilms tumor in aniridia patients. Am J Med Genet 108:285289, 2002

48. Pischon $T$, Boeing $H$, Hoffmann $K$, et al: General and abdominal adiposity and risk of death in Europe. N Engl J Med 359:2105-2120, 2008

49. Oeffinger KC, Mertens AC, Sklar CA, et al: Chronic health conditions in adult survivors of childhood cancer. N Engl J Med 355:1572-1582, 2006

50. Woodwell DA, Cherry DK: National Ambulatory Medical Care Survey: 2002 Summary (Report No. 346). Hyattsville, MD, National Center for Health Statistics, 2004 
51. Ness KK, Mertens $A C$, Hudson $M M$, et al: Limitations on physical performance and daily activities among long-term survivors of childhood cancer. Ann Intern Med 143:639-647, 2005

52. Arena VC, Padiyar KR, Burton WN, et al: The impact of body mass index on short-term disability in the workplace. J Occup Environ Med 48:11181124, 2006
53. Guallar-Castillón P, Sagardui-Villamor J, Banegas JR, et al: Waist circumference as a predictor disability among older adults. Obesity 15:233-244, 2007

54. Harkonmäki K, Korkeila K, Vahtera J, et al: Childhood adversities as a predictor of disability retirement. J Epidemiol Community Health 61:479484, 2007
55. McLaughlin KA, Borkovec TD, Sibrava NJ: The effects of worry and rumination on affect states and cognitive activity. Behav Ther 38:23-38, 2007

56. Ness KK, Leisenring WM, Huang $S$, et al: Predictors of inactive lifestyle among adult survivors of childhood cancer: A report from the Childhood Cancer Survivor Study. Cancer 115: 1984-1994, 2009

\section{ATTEND THE 2012 GENITOURINARY CANCERS SYMPOSIUM}

Join us in San Francisco for the 2012 Genitourinary Cancers Symposium (February 2-4, 2012), where the latest clinical and scientific strategies in screening, evaluation, and management of genitourinary cancers will be discussed. The Symposium offers multidisciplinary education sessions, as well as oral and poster abstract presentations on prostate, penile, urethral, testicular, renal, and urothelial cancers. Bookmark gucasymposium.org and visit regularly for meeting updates. The abstract submitter, registration, and housing selection features are now open. 